\title{
Comparing the Relationship between Focus of Attention and Attention Bias in Suicide and Non-suicide Attempters

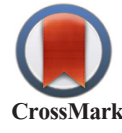

Imanollah Bigdeli ${ }^{* *}$, Fatemeh Ghassem Boroujerdi ${ }^{1}$, Farzaneh Haji Zadeh ${ }^{2}$, Zeinab Golchehreh Rahimi ${ }^{1}$, Masoomeh Mihan Dust ${ }^{3}$

1. Department of Psychology, Faculty of Education and Psychology, Ferdowsi University of Mashhad, Mashhad, Iran.

2. Department of Psychology, Faculty of Psychology and Education, Allameh Tabataba'i University, Tehran, Iran.

3. Department of Psychology, Faculty of Psychology and Education, Shahre Qods Branch, Islamic Azad University, Tehran, Iran.

Citation: Bigdeli, I., Ghassem Boroujerdi, F., Haji Zadeh, F., Golchehreh Rahimi, Z., \& Mihan Dust, M. (2016). Comparing the Relationship between Focus of Attention and Attention Bias in Suicide and Non-Suicide Attempters. Journal of Practice in Clinical Psychology, 4(3), 151-158. http://dx.crossref.org/10.15412/J.JPCP.06040302

: http://dx.crossref.org/10.15412/J.JPCP.06040302

\section{Article info:}

Received: 01 Mar. 2016

Accepted: 02 Jun. 2016

\section{Keywords:}

Attention, Cognitive function, Suicide

\begin{abstract}
A BSTRACT
Objective: Suicide rate is unfortunately increasing in recent years and its assessment is a must. Most studies have evaluated different factors like personality, depression, or environment in suicide attempters but cognitive functions have been overlooked in suicide attempters. The current research aimed to evaluate a kind of cognitive function, namely attention in survivors of suicide.

Methods: This case-control study was conducted in Tehran, Iran in 2015. Two groups of patients one with recent suicide attempts and the other one with no suicide attempt were compared in domains of focus of attention and attention bias. A total of 18 patients participated in each group. Instruments used for this research included questionnaire of focus of attention and simple stroop test software. Correlation of these 2 instruments was compared between groups. Data were analyzed by the independent t-test, ANOVA, and the Pearson correlation.
\end{abstract}

Results: Mean age of suicide attempters was 29.5 years which was significantly lower than that in the control group and most of them were women. They spent more time in recognizing incongruent stimulus, congruent, and incongruent response. The time that was spent on experiment of incongruent stimulus, congruent, and incongruent response was significantly higher in suicide attempters. In suicide attempters, there was a significant correlation between number of congruent and incongruent errors with focus of attention.

Conclusion: Our results showed that attention as a cognitive function may be impaired in suicide attempters. Thus, it is necessary to recognize cognitive functions of suicide attempters along with other comorbid psychological factors for preventing future suicide attempts and eventually losing precious lives.

\section{Introduction}

uicide is the act of causing self's death intentionally. It is often due to despair, psychiatric disorders such as depression, bipolar disorder, schizophrenia and borderline personality disorder (Paris, 2002).

Suicide has resulted in 842000 deaths in 2013. This number was more than 712000 deaths in 1990 (GBD,

* Corresponding Author:

Imanollah Bigdeli, $P h D$

Address: Department of Psychology, Faculty of Education and Psychology, Ferdowsi University of Mashhad, Mashhad, Iran.

Tel: +98 (912) 1317800

E-mail: ibigdeli@um.ac.ir 
2013), which makes it the 10th leading cause of death worldwide (Hawton \& van Heeringen, 2009; Varnik, 2012). Suicide rate has increased up to $60 \%$ from 1960 s to 2012 (The World Health Organization, 2012) and this increase has been seen primarily in the developing world (Hawton \& van Heeringen, 2009). Regarding the percentage of deaths in 2008 , suicide accounts for $0.5 \%$ of deaths in Africa, 1.9\% in Southeast Asia, 1.2\% in America, and $1.4 \%$ in Europe. In the Eastern Mediterranean, region, suicide rate is nearly equivalent between males and females Varnik, 2012). Rate of successful suicide is higher in men than in women, with males 3 to 4 times more likely to kill themselves than females (Meier \& Clinard, 2008).

The most commonly used method of suicide varies by country and is partly related to available resources. Common methods include hanging, pesticide poisoning, and firearms (Ajdacic-Gross et al., 2008).

It is estimated that 10 to 20 million people attempt incomplete suicide per year (Bertolote \& Fleischmann, 2002). Indeed, attempted suicide or non-fatal suicidal behavior reflects the self-injury with the desire to die, but does not result in death (Krug, 2002). Non-fatal suicide attempts may result in injuries or irrecoverable physical disabilities. In the Western world, suicide attempts are more common in young people and females. There are between 10 to 40 attempted suicides, for every successful suicide (Chang, Gitlin, \& Patel, 2011).

In mental health patients, lifetime rate of suicide has increased to as much as $10 \%$ in borderline personality disorder (Paris, 2002) and 29.2\% in bipolar disorder (Chen \& Dilsaver, 1996). Depression is the most common psychiatric disorder in people who die by suicide. It is strongly associated with suicide and non-fatal suicidal behaviors (Hawton \& van Heeringen, 2009).

People who had suffered from mood fluctuations or depression within the last year and had frequent difficulty in focusing attention within the past week are more likely to receive mental health services. Therefore, emotion regulations like daily mood fluctuations and neurocognitive factors play important role in the clinical assessment of people with suicide preoccupation (Alonzo, Conway, \& Modrek, 2016). People committing suicide with carbon monoxide poisoning have worse cognitive performance in domains of attention, memory, and executive function compared with people without the history of suicide (Yang et al., 2015). Indeed, cognitive factors like attention and it's components like "focus of attention" and "attention bias" are also important in suicide behavior. Attention is the intentional behavior and cognitive process of concentration on specific information, and neglecting other perceivable ones. It can be subjective or objective. In the process of attention, limited cognitive and behavioral resources are allocated (Anderson, 2004). The best description of focus of attention is the sustained focus of cognitive potentials on information while ignoring extraneous materials (Sohlberg \& Mateer, 1989).

Attentional bias is the tendency of our perception to be affected by our recurring thoughts (Bar-Haim, Lamy, Pergamin, Bakermans-Kranenburg, \& van Ijzendoorn, 2007). Higher levels of suicidal ideas and attempts exist in people with attention deficit like Attention Deficit Hyperactivity Disorder (ADHD), than in people with normal attention. The rate of ADHD in suicidal population is consistently high. Meta-analysis has identified a relationship between ADHD and suicide (Impey \& Heun, 2012).

As we investigated studies about attention or cognitive functions in suicide attempters, it becomes obvious that most studies have evaluated attention components in the domain of patients with attention deficit or in connection with some other cognitive functions. Unfortunately, we lack enough knowledge, especially in our country about the attention components in suicide attempters. However, our current research is rather a new topic in considering the correlation between two components of attention in suicide attempters.

According to previous studies, cognitive functions may play important role in depressed people who are at risk of suicide attempt. Indeed, the life is the most precious factor of the world. Losing this precious factor by suicide is really painful and tragic. Thus, we should try to identify it more accurately. By having a better knowledge of suicide, we will be more expert in preventing it. Due to lack of enough research in cognitive functions in suicide attempters, especially attention field, our goal in current research was to compare the focus of attention and attention bias between suicide attempters and control group and evaluation of their relationship. Our hypotheses are that there is a correlation between attention bias and focus of attention and there are differences between suicide attempters and control group regard to them.

\section{Methods}

This is a case-control study. This study was done in Loghman Hospital in Tehran from October to November 2015. We investigated focus of attention and attention bias in 2 groups. One group included suicide attempters (case group) and the other group included patients without the history of suicide attempt (control group). The sample group were hospitalized in Emergency ward 
and comprised 36 participants. A total of 18 people were in the case group and 18 in the control group. The sampling method was convenient and the study was done on volunteers, which justify the low sample size of 18 people in each group. The statistical population included all hospitalized patients in Emergency ward of Loghman Hospital in Tehran, including suicide attempters and non-suicide attempters. Data were obtained from participants according to the Helsinki Declaration (1975). The project was confirmed in ethics and scientific committee of the Loghman Hospital with the code No. 3309. The main purposes of the study were explained to the participants. All participants gave informed consents before participation in the research and we assured them that their personal information will not be disclosed, and be used just for scientific purposes.

Instruments used for this research included questionnaire of focus of attention and simple stroop test. A professional and trained psychologist gathered information from participants. At first, she obtained demographic information and their history of suicide behaviour. Then, the psychologist debriefed and gave complete information about two instruments. Next, the participants completed the paper-pencil questionnaire of focus of attention and computerized stroop test.

Questionnaire of focus of attention was developed in 1997. It has 10 questions with 2 subscales, including self-focused attention and social-focused attention. Likert system is used for its scoring (Woody, Chambless, $\&$ Glass, 1997). The reliability of the questionnaire with the Cronbach $\alpha$ in Iranian validation has been reported to be $75 \%$ for self-focused attention and $86 \%$ for socialfocused attention (Khayyer, Ostovar, Latifian, Taghavi, $\&$ Samani, 2008). In addition, the validity of the questionnaire has been confirmed (Woody et al., 1997).

Stroop test was developed in 1935 for measuring selective attention and cognitive flexibility by visual processing. In this software test, written form of 4 colors are shown to the person in congruent or incongruent colors and the person should immediately respond to colors that have been written in different color names (Khodadadi, Mashhadi, \& Amani, 2014). Different studies have showed the validity and reliability of the test (MacLeod, 1991). The test-retest reliability of the test has been reported to be 0.8 to 0.91 (Lezak, Howieson, \& Loring, 2004).

Inclusion criteria in suicide attempter group included informed consent, being more than 18 years old, having complete consciousness, being hospitalized because of suicide attempt. Exclusion criteria for the suicide at- tempter group included no tendency for continuing the participation in the project, deterioration of the physical state, discharging from the hospital, being in toxication or withdrawal of drugs or substance state, as well as having the history of suicide attempt for the control group. Data were analyzed by descriptive statistics, the independent $\mathrm{t}$ test, ANOVA, and the Pearson correlation using SPSS-21.

\section{Results}

A total of 21(58.3\%) participants were female and $15(41.7 \%)$ were male. Their mean(SD) age was $34.28(12.22)$ years. In terms of education, $19.4 \%$ had lower than high school diploma, $47.2 \%$ had high school diploma or associate degree, $30.6 \%$ had bachelor and master degree, and $2.8 \%$ had doctorate degree. In terms of occupation, $16.7 \%$ were housewife, $5.6 \%$ jobless, $8.3 \%$ student, $13.9 \%$ employee, and $55.6 \%$ self-employed. In terms of marital status, $50 \%$ were married, $47.2 \%$ were single, and $2.8 \%$ were divorced or widowed.

In the case group, 10 were female and 8 were male. Their mean(SD) age was 29.5(8.21) years. Eight were married and 10 were single. Education of 6 of them was lower than diploma, 9 had diploma and associate degree, 3 had bachelor and master degree, 4 were housewife, 2 were jobless, 1 was student, 1 was employee, and 10 were self-employed.

In the control group, 11 were female and 7 were male, 10 were married, 7 were single and 1 was widowed. Their mean(SD) age was 39.06(13.84) years. Education of 1 of them was lower than diploma, 8 had diploma or associate degree, 8 had bachelor or master degree and 1 had doctorate level. Two were housewife, 2 were student, 4 were employee, and 10 were self-employed.

There was a significant difference between two groups in attention bias, congruent stimulus experiment time, congruent response time, incongruent response time ( $\mathrm{P}=0.05)$, (Table-1).

ANOVA test showed a significant difference with regard to mean age of 2 groups $(\mathrm{P}<0.01)$. So that the mean age of suicide attempters was lower than that in the control group. There were also significant differences between the education degrees of 2 groups $(\mathrm{P}<0.001)$. So that suicide attempters had lower educational level.

ANOVA test showed that the time spent on experiment of incongruent stimulus was significantly higher in suicide attempters $(\mathrm{P}=0.05, \mathrm{Sig} .=0.031)$. Suicide attempters spent significantly more time on congruent response $(\mathrm{P}=0.05$, 
Table 1. Independent t-test results of stroop test.

\begin{tabular}{|c|c|c|c|c|c|c|}
\hline Variable & $\begin{array}{l}\text { Mean } \\
\text { (Case } \\
\text { group) }\end{array}$ & $\begin{array}{c}\text { Mean } \\
\text { (Control group) }\end{array}$ & $\begin{array}{c}\text { SD } \\
\text { (Case group) }\end{array}$ & $\begin{array}{c}\text { SD } \\
\text { (Control group) }\end{array}$ & $\mathbf{P}$ & $\mathbf{T}$ \\
\hline $\begin{array}{c}\text { Congruent stimulus experiment } \\
\text { time }\end{array}$ & 56.39 & 47.17 & 14.368 & 10.188 & $0.032 *$ & 2.29 \\
\hline $\begin{array}{l}\text { Incongruent stimulus experi- } \\
\text { ment time }\end{array}$ & 59.44 & 14.177 & 12.821 & 12.868 & $0.057^{*}$ & 1.97 \\
\hline No. of congruent mistakes & 0.83 & 2.149 & 2.149 & 0.236 & 0.145 & 1.52 \\
\hline No. of incongrunet mistakes & 4.28 & 3.61 & 3.308 & 1.875 & 0.541 & 0.62 \\
\hline No congruent response & 4.56 & 0.56 & 8.347 & 0.992 & 0.059 & 2.021 \\
\hline No incongruentresponse & 6.11 & 1.94 & 10.566 & 4.588 & 0.133 & 1.55 \\
\hline No. of correct congruent & 42.61 & 47.39 & 10.071 & 1.092 & 0.061 & 2.001 \\
\hline N. correct incongruent & 37.61 & 13.095 & 13.095 & 6.297 & 0.176 & -1.395 \\
\hline Congruentresponse time & 1147.67 & 983.67 & 266.812 & 182.377 & $0.028^{*}$ & 2.309 \\
\hline Incongruentresponse time & 1146.22 & 1035.89 & 260.608 & 199.945 & $0.030 *$ & 2.271 \\
\hline Interferencescore & 5.33 & 5.28 & 3.816 & 5.949 & 1.00 & 0.00 \\
\hline Interference time & 108.22 & 68.89 & 36.706 & 42.791 & 0.829 & 0.217 \\
\hline
\end{tabular}

Time unit: second

Table 2. Independent t-test results of focus of attention.

\begin{tabular}{ccccccc}
\hline Variable & $\begin{array}{c}\text { Mean } \\
\text { (Case group) }\end{array}$ & $\begin{array}{c}\text { Mean } \\
\text { (Control group) }\end{array}$ & $\begin{array}{c}\text { SD } \\
\text { (Case group) }\end{array}$ & $\begin{array}{c}\text { SD } \\
\text { (Control group) }\end{array}$ & P & T \\
\hline Focus of self-attention & 14.89 & 16.44 & 3.787 & 3.347 & 0.200 & -1.306 \\
\hline Focus of social attention & 14.22 & 16.28 & 4.660 & 3.375 & 3.375 & -1.516 \\
\hline Total score & 1.50 & 1.67 & 0.618 & 0.767 & 0.478 & -0.718 \\
\hline & & & & & $\begin{array}{c}\text { PRACTICE in } \\
\text { CLINICAL PSCH LOSY }\end{array}$ \\
\hline
\end{tabular}

Sig. $=0.27)$ and incongruent response $(\mathrm{P}=0.05$, Sig. $=0.030)$. Furthermore, There was no difference between 2 groups with regard to attention focus score (Table 2).

Results of correlation analysis showed that in suicide attempters, there is a strong and reverse correlation between the number of congruent errors and self-attention $(\mathrm{P}=0.05)$, a strong correlation between the number of congruent errors and focus of attention $(\mathrm{P}=0.05)$, a strong and reverse correlation between the number of incongruent errors and selfattention $(\mathrm{P}=0.05)$, a strong correlation between the number of incongruent errors and focus of attention $(\mathrm{P}=0.05)$ and a strong and reverse correlation between the number of correct congruent and focus of attention $(\mathrm{P}=0.05)$ (Table 3 ). Finally, in the control group, there is a strong and reverse correlation between focus of control and congruent stimu- lus experiment time $(\mathrm{P}=0.05)$, congruent response time $(\mathrm{P}=0.05)$ and incongruent response time $(\mathrm{P}=0.05)$ (Table 4$)$.

\section{Discussion}

According to the results of current study, attention field is an important factor in the suicide attempters. Our results showed that suicide attempters compared to control group were younger, most of them were single, had lower education level, and some of them were jobless. Attention bias components, but not focus of attention, were different between 2 groups. Suicide attempters spent more time in recognizing incongruent stimulus, congruent, and incongruent response, which may show that suicide attempters cannot concentrate on correct items and spend more time in tasks needing precise attention. Some studies show that attention interference is correlated slightly 
Table 3. The Pearson correlation test results between focus of attention and stroop test in suicide attempters.

\begin{tabular}{|c|c|c|c|}
\hline Variables & Self-attention & Social-attention & Focus of attention \\
\hline Congruent stimulus experiment time & 0.75 & -0.090 & 0.146 \\
\hline P-value & 0.767 & 0.723 & 0.564 \\
\hline Incongruent stimulus experiment time & 0.093 & -0.108 & 0.104 \\
\hline P-value & 0.713 & 0.670 & 0.681 \\
\hline No. of congruent errors & $-0.516^{*}$ & -0.460 & $0.553^{*}$ \\
\hline P-value & 0.28 & 0.055 & 0.017 \\
\hline No. of incongruent errors & $-0.510^{*}$ & -0.430 & $0.518^{*}$ \\
\hline P-value & 0.30 & 0.075 & 0.028 \\
\hline Without congruent response & -0.173 & -0.130 & 0.444 \\
\hline P-value & 0.493 & 0.606 & 0.065 \\
\hline Without incongruent response & -0.88 & -0.113 & 0.351 \\
\hline P-value & 0.729 & 0.960 & 0.153 \\
\hline No. of correct congruent & 0.200 & 0.206 & $-0.486 *$ \\
\hline P-value & 0.427 & 0.412 & 0.041 \\
\hline No. of correct incongruent & 0.199 & 0.200 & -0.414 \\
\hline P-value & 0.427 & 0.427 & 0.088 \\
\hline Congruent response time & 0.31 & -0.013 & 0.018 \\
\hline P-value & 0.858 & 0.960 & 0.946 \\
\hline Incongruent response time & 0.236 & -0.01 & -0.032 \\
\hline P-value & 0.345 & 0.996 & 0.899 \\
\hline Interference score & 0.034 & -0.125 & 0.112 \\
\hline P-value & 0.892 & 0.620 & 0.658 \\
\hline Interference time & 0.215 & 0.176 & -0.143 \\
\hline P-value & 0.391 & 0.484 & 0.573 \\
\hline
\end{tabular}

$* \mathrm{P}=0.05$.

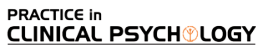

Time unit: second

with depression, daily functioning, suicide preoccupation, number of suicide attempts, and their lethality in the past (Keilp, Gorlyn, Oquendo, Burke, \& Mann, 2008).

Meanwhile, in the control group of our study, higher focus of attention was correlated with less time spent in recognizing congruent stimuli and responding to them. In suicide attempters, with high self-attention, congruent and incongruent errors decrease, which may mean that they can reduce their different visual mistakes by paying enough attention to themselves. They also showed increased mistakes in recognizing similar and different stimuli, by increased focus of attention. This is a strange finding, because it means that when they try to augment their attention focus, they lose the ability to distinguish similar and various stimuli. Some studies show that attention is impaired in all depressed subjects but worse in those with a past history of suicidal behavior (Keilp et al., 2008). Stroop interference is also significantly poorer in depressed patients, and poorer in suicide attempters who had used serious lethal methods (Keilp et al., 2008). All these findings show the irregularity in attention function of suicide attempters.

Most studies in this field showed the cognitive impairment in suicide attempters and were similar to our findings. Most suicide attempters are depressed. A number of psychological states such as hopelessness, loss of pleasure in life, depression, and anxiousness increase the risk of suicide (Chehil \& Kutcher, 2012). Depres- 
Table 4. The Pearson correlation test results between focus of attention and stroop test in the control group.

\begin{tabular}{|c|c|c|c|}
\hline Variables & Self-attention & Social-attention & Focus of attention \\
\hline Congruent stimulus experiment time & 0.09 & -0.038 & $-0.484 *$ \\
\hline P-value & 0.721 & 0.881 & 0.042 \\
\hline Incongruent stimulus experiment time & 0.09 & -0.39 & -0.431 \\
\hline P-value & 0.722 & 0.877 & 0.074 \\
\hline No. of congruent error & -0.018 & -0.168 & -0.217 \\
\hline P-value & 0.671 & 0.504 & 0.387 \\
\hline No. of incongruent error & 0.114 & -0.107 & -0.300 \\
\hline P-value & 0.654 & 0.671 & 0.227 \\
\hline No congruent response & 0.258 & -0.109 & -0.139 \\
\hline P-value & 0.200 & 0.666 & 0.583 \\
\hline No incongruent response & 0.191 & -0.017 & -0.145 \\
\hline P-value & 0.441 & 0.947 & 0.566 \\
\hline No. of correct congruent & -0.195 & 0.129 & 0.164 \\
\hline P-value & 0.438 & 0.611 & 0.516 \\
\hline No. of correct incongruent & -0.173 & 0.04 & 0.195 \\
\hline P-value & 0.492 & 0.861 & 0.438 \\
\hline Congruent response time & -0.002 & -0.040 & $-0.520 *$ \\
\hline P-value & 0.997 & 0.874 & 0.020 .02 \\
\hline Incongruent response time & 0.014 & -0.051 & $-0.489 *$ \\
\hline P-value & 0.957 & 0.842 & 0.040 \\
\hline Interference score & 0.222 & -0.46 & 0.228 \\
\hline P-value & 0.375 & 0.857 & 0.363 \\
\hline Interference time & 0.029 & -0.043 & -0.155 \\
\hline P-value & 0.908 & 0.864 & 0.540 \\
\hline
\end{tabular}

${ }^{*} \mathrm{P}=0.05$.

Time unit: second

sive symptoms, family socioeconomic status, familial situation, relationship with parents, school situation, and substance use are significant independent predictors of lifetime suicide attempts (Roscoät, Legleye, Guignard, Husky, \& Beck, 2016). Adolescents with depression show impaired attention. Two executive dysfunction are recognized in patients with major depression disorder. Orienting performance is more impaired in those with a history of comorbid substance use disorder, and alertness is more impaired in those with a history of a suicide attempt (Sommerfeldt et al., 2015). Depression-related impairments of attention, especially susceptibility to interference, are accentuated in those with a past history of suicidal behavior (Keilp et al., 2008).
Anxiety sensitivity cognitive concerns are robust predictor of elevated suicide risk after covarying for negative affect (Oglesby, Capron, Raines, \& Schmidt, 2015). A poor ability to solve problems, the loss of abilities one used to have, and poor impulse control also play a role in suicide high risk (Chehil \& Kutcher, 2012; Roscoät et al., 2016; Sommerfeldt et al., 2015; Oglesby et al., 2015; Joiner, Brown, \& Wingate, 2005). Furthuremore, increased risk of suicide is found in people with self-neglect and also in those with impaired memory (Barraclough \& Pallis, 1975). Also, there is a strong and significant association between decision-making which is a cognitive function and the risk of suicidal behavior in unipolar disorder and bipolar disorder (Richard-Devantoy, Olié, Guillaume, 
$\&$ Courtet, 2016). Anxiety sensitivity cognitive concerns are strong predictor of suicide risk, especially when accompanying with negative affect (Oglesby et al., 2015). Poor coping strategies, the loss of abilities one used to have, and poor impulse control also play important role in suicide high risk (Chehil \& Kutcher, 2012; Roscoät et al., 2016; Sommerfeldt et al., 2015; Oglesby et al., 2015; Joiner et al., 2005). In addition, increased risk of suicide is found in people who pay little attention to themselves and have impaired memory (Barraclough \& Pallis, 1975).

Also, there is a strong significant association between decision-making as a cognitive function and the risk of suicidal behavior in patients with mood disorder (Richard-Devantoy et al., 2016). Executive deficits are broadly associated with suicidal preoccupation in older depressed adults but do not directly facilitate suicidal behavior (Gujral et al., 2014). Fundamental deficits in attention process may play a role in suicidal behavior risk. They may contribute to a variety of cognitive dysfunctions in suicidal patients. Brain regions subserving attentional control, which overlap considerably with regions implicated in affective disorders, may be an applicable target for studies seeking to recognize neuropsychological factors that play role in suicidal behavior (Keilp et al., 2008).

All in all, considering the role of cognitive functions like attention in suicide attempters is important (especially in people who are at high risk for suicide) for planning precise and psychological treatment and eventually prevent the tragic loss of humans.

We had some limitations in our study. Generally, there is limited access to suicide attempter survivors which may be due to reluctance in reporting the suicide attempt in our country. This problem caused the limited number of our sample group. In addition, some of suicide attempters had harmful physical situations that made the research so difficult for further process.

Regarding the role of diversive factors in suicide attempting in different cultures and domains, we hope that future suicide researchers invest more in evaluating cognitive functions like attention, information processing, memory, etc. and their probable deficiencies in suicide attempters. By recognizing cognitive functions of suicide attempters, it is possible to provide treatment protocols and suicide prevention programs. Because, we seriously lack enough knowledge in this important field which is directly connected with the most precious issue of the world, life, working on finding more knowledge in suicide domain may enhance the life quality of people who are at the risk of suicide.

\section{Acknowledgements}

The current research hasn't received any financial support.

\section{Conflict of Interests}

The authors declared no conflict of interests.

\section{References}

Ajdacic-Gross, V., Weiss, M. G., Ring, M., Hepp, U., Bopp, M., Gutzwiller, F., et al. (2008). Methods of suicide: international suicide patterns derived from the WHO mortality database. Bulletin of World Health Organization, 86(9), 726-32.

Alonzo, D., Conway, A., \& Modrek, A. S. (2016). Latino suicidal adolescent psychosocial service utilization: the role of mood fluctuations and inattention. Journal of Affective Disorders, 190, 616-22.

Anderson, J. R. (2004). Cognitive psychology and its implications. New York: Worth Publishers.

Bar-Haim, Y., Lamy, D., Pergamin, L., Bakermans-Kranenburg, M. J., \& van Ijzendoorn, M. H. (2007). Threat-relatade attentional bias in anxious and non-anxious individuals: a metaanalytic study. Psychological Bulletin, 133(1), 1-24.

Barraclough, B. M., \& Pallis, D. J. (1975). Depression followed by suicide: a comparison of depressed suicides with living depressives. Psychological Medicine, 5(1), 55-61.

Bertolote, J. M., \& Fleischmann, A. (2002). Suicide and psychiatric diagnosis: a world wide perspective. World Psychiatry, 1(3), 181-85.

Chang, B., Gitlin, D., \& Patel, R. (2011). The depressed patient and suicidal patient in the emergency department: evidencebased management and treatment strategies. Emergency Medicine Practice, 13(9), 1-23.

Chehil, S., \& Kutcher, S. P. (2012). Suicide risk management: a manual for health professionals. Chicester: John Wiley \& Sons.

Chen, Y., \& Dilsaver, S. (1996). Lifetime rates of suicide attempts among subjects with bipolar and unipolar disorders relative to subjects with other Axis I disorders. Biological Psychiatry, 39(10), 896-99.

Global Burden of Diseases. (2013). Global, regional, and national age-sex specific all-cause and cause-specific mortality for 240 causes of death, 1990-2013: a systematic analysis for the global burden of disease study. Lancet, 385(9963), 117-71.

Gujral, S., Dombrovski, A. Y., Butters, M., Clark, L., Reynolds, C. F., \& Szanto, K. (2014). Impaired executive function in contemplated and attempted suicide in late life. American Journal of Geriatric Psychiatry, 22(8), 811-19.

Hawton, K., Comabella, C. C., Haw, C., \& Saunders, K. (2013). Risk factors for suicide in individuals with depression: a systematic review. Journal of Affective Disorders, 147(1-3), 17-28. 
Hawton, K., \& van Heeringen, K. (2009). Suicide. Lancet, 373(9672), 1372-381.

Impey, M., \& Heun, R. (2012). Completed suicide, ideation and attempt in attention deficit hyperactivity disorder. Acta Psychiatrica Scandinavica, 125(2), 93-102.

Joiner, T. E., Brown., J. S., \& Wingate, L. R. (2005). The psychology and neurobiology of suicidal behavior. Annual Review of Psychology, 56, 287-314.

Keilp, J. G., Gorlyn, M., Oquendo, M. A., Burke, A. K., \& Mann, J. J. (2008). Attention deficit in depressed suicide attempters. Psychiatry Research, 159(1), 7-17.

Khayyer, M., Ostovar, S., Latifian, M., Taghavi, M. R., \& Samani, S. (2008). [The study of mediating effects of self-focused attention and social self-efficacy on links between social anxiety and judgment biases (Persian)]. Iranian Journal of Psychiatry and Clinical Psychology, 14(1), 24-32.

Khodadadi, M., Mashhadi, A., \& Amani, H. (2014). [Simple Stroop Sofware (Persian)]. Tehran: Institute for Behavioral \& Cognitive Sciences.

Krug, E. G. (2002). World report on violence and health (Vol. 1). Genève: World Health Organization.

Lezak, M. D., Howieson, D. B., \& Loring, D. W. (2004). Neuropsychological assessment. New York: Oxford University Press.

MacLeod, C. M. (1991). Half a century of research on the Stroop effect: an integrative review. Psychological Bulletin, 109(2), 163-203.

Meier, M. B., \& Clinard, R. F. (2008). Sociology of deviant behavior. Belmont, C.A.: Wadsworth Cengage Learning.

Oglesby, M. E., Capron, D. W., Raines, A. M., \& Schmidt, N. B. (2015). Anxiety sensitivity cognitive concerns predict suicide risk. Psychiatry Research, 226(1), 252-56.

Paris, J. (2002). Chronic suicidality among patients with borderline personality disorder. Psychiatric Services, 53(6),738-42.

Richard-Devantoy, S., Olié, E., Guillaume, S., \& Courtet, P. (2016). Decision-making in unipolar or bipolar suicide attempters. Journal of Affective Disorders, 190, 128-36.

Roscoät, E. D., Legleye, S., Guignard, R., Husky, M., \& Beck, F. (2016). Risk factors for suicide attempts and hospitalizations in a sample of 39,542 French adolescents. Journal of Affective Disorders, 190, 517-21.

Sohlberg, M. M., \& Mateer, C. A. (1989). Introduction to cognitive rehabilitation: therapy and practice. New York: Guilford Press.

Sommerfeldt, S. L., Cullen, K. R., Han., G., Fryza, B. J., Houri, A. K., \& Klimes-Dougan, B. (2016). Executive attention impairment in adolescents with major depressive disorder. Journal of Clinical Child and Adolescent Psychology, 45(1), 69-83. doi: 10.1080/15374416.2015.1072823

Värnik, P. (2012). Suicide in the world. International Journal of Environmental Research and Public Health, 9(3), 760-71.

World Health Organization. (2012). Suicide Prevention [Internet]. Retrieved from http://www.who.int/mental_health/prevention/suicide/suicideprevent/en
Woody, S. R., Chambless, D. L., \& Glass, C. R. (1997). Self-focused attention in the treatment of social phobia. Behaviour Research and Therapy, 35(2), 117-29.

Yang, K. C., Wang, S. J., Hsieh, W. C., Lirng, J. F., Yang, C. C., Deng, J. F., et al. (2015). Longitudinal changes in the dopamine transporter and cognition in suicide attempters with charcoal burning. Psychiatry Research: Neuroimaging, 231(2), $160-67$ 